\title{
Project and Community Management in Polar Sciences - Challenges and Opportunities
}

\author{
Kirstin Werner ${ }^{1}$, Yulia Zaika ${ }^{2}$, Alexey K. Pavlov ${ }^{3,4}$, Sven Lidström ${ }^{5}$, Allen Pope ${ }^{6}$, Renuka Badhe ${ }^{7}$, Marlen Brückner ${ }^{8}$, \\ and Luisa Cristini ${ }^{9}$ \\ ${ }^{1}$ Year of Polar Prediction International Coordination Office, Alfred Wegener Institute, Helmholtz Centre for Polar \\ and Marine Research, Bremerhaven, Germany \\ ${ }^{2}$ Khibiny Research Station, Faculty of Geography, Lomonosov Moscow State University, Moscow, Russia \\ ${ }^{3}$ Institute of Oceanology Polish Academy of Sciences, Sopot, Poland \\ ${ }^{4}$ Akvaplan-niva, Troms $\emptyset$, Norway \\ ${ }^{5}$ Norwegian Polar Institute, Troms $\varnothing$, Norway \\ ${ }^{6}$ International Arctic Science Committee IASC Executive Secretariat, Akureyri, Iceland \\ ${ }^{7}$ European Polar Board, The Hague, the Netherlands \\ ${ }^{8}(\mathrm{AC})^{3}$ Scientific Coordination Office, Institute for Meteorology, University of Leipzig, Germany \\ ${ }^{9}$ APPLICATE Project Management Office, Alfred Wegener Institute, Helmholtz Centre for Polar and Marine Research, \\ Bremerhaven, Germany
}

Correspondence: Kirstin Werner (kirstin.werner@awi.de)

Received: 29 June 2018 - Revised: 7 March 2019 - Accepted: 18 March 2019 - Published: 29 April 2019

\begin{abstract}
Because geoscientific research often occurs via community-instigated bursts of activity with multiinvestigator collaborations variously labelled as e.g., years (The International Polar Year IPY), experiments (World Ocean Circulation Experiment WOCE), programs (International Ocean Discovery Program), missions (CRYOSAT spacecraft), or decades (The International Decade of Ocean Exploration IDOE), successful attainment of research goals generally requires skilful scientific project management. In addition to the usual challenges of matching scientific ambitions to limited resources, on-going coordination and specifically project management, planning and implementation of polar science projects often involve many uncertainties caused by, for example, unpredictable weather or ocean and sea ice conditions, large-scale logistical juggling; and often these collaborations are spatially distributed and take place virtually. Large amounts of funding are needed to procure the considerable infrastructure and technical equipment required for polar expeditions; permissions to enter certain regions must be requested; and potential risks for expedition members as well as technical issues in extreme environments need to be considered. All these aspects are challenging for polar science projects, which therefore need a well thought-
\end{abstract}

through program including a realistic alternative "plan B" and possibly also a "plan C" and "plan D".

The four most challenging overarching themes in polar science project management have been identified: international cooperation, interdisciplinarity, infrastructure, and community management. In this paper, we address ongoing challenges and opportunities in polar science project management based on a survey among 199 project and community managers and an additional of 85 project team members active in the field of polar sciences. Case studies and survey results are discussed with the conclusive goal to provide recommendations on how to fully reach the potential of polar sciences project and community management.

\section{Introduction}

Polar regions have undergone dramatic environmental changes in the past decades due to ongoing global climate change. As key areas for understanding the current state and future changes in Earth's climate system, both the Arctic and Antarctica have brought the attention of the international research community and the public. Furthermore, re- 
treating Arctic sea-ice cover, thawing permafrost, melting ice sheets and glaciers, and associated environmental changes have made the polar seas and particularly the Arctic Ocean more accessible, therefore providing new logistical and planning challenges.

As modern science increasingly advances through collaborative projects, effective project management plays an increasingly essential role also for projects in academia. Developed for very different sectors (Kloppenborg and Opfer, 2002), project management provides the scientific community with a set of processes usefully applicable to scientific activities in the field, laboratory, and beyond. Different processes of project management such as initiating, planning, executing, controlling, and closing (Project Management Institute, 2017) allow research projects to be carried out in an organised and sensible way, resulting in increased chances of successful science project delivery. However, managing a research project can be particularly uncertain due to its complexity involving 'substantial elements of creativity and innovation' which sometimes makes it difficult to predict the outcome of research in full (Ernø-Kjølhede, 2000). Therefore, project management in academia as true also for other domains must be kept flexible and adaptable as new discoveries along the way may request adjustment for unforeseen scenarios where specific outcomes, end dates, or budgets can change (Kridelbaugh, 2017). Polar research is particularly challenging as communities are dispersed across the globe, in addition to the considerable logistical challenges given the extreme environments and inaccessibility.

Project management in polar sciences includes peculiarities and specifics applicable to polar environments only. With ongoing environmental changes in polar regions in the past few decades, the Arctic, Antarctic, and the "Third Pole" (High Mountain regions) have become a focus for sustained research. Planning and implementation of research projects in these areas often involve many additional organizational uncertainties, including large budgets, complicated logistics, unique risk management, and international and interdisciplinary collaboration. While these issues need to be considered by the operating personnel, there is extra, mostly weather-driven, uncertainty and complexity for operations in polar regions that makes it even more important for the project management to be efficient, effective and professional to support their colleagues' science activities in the field, laboratory, and office.

An important challenge in a cross-disciplinary endeavour such as polar sciences is the diversity of perspectives of the people involved (Dewulf et al., 2007). While team science has led to scientific breakthroughs that would otherwise not have been possible, conducting collaborative research can be challenging as for example extra time is required for the communication and coordination of team work (National Research Council, 2015). With diverse and often dispersed teams, community engagement is therefore crucial for sustained success in polar science, in particular for initiating and growing support for large international and interdisciplinary projects. While complicated, polar sciences is still a human endeavour where dedicated facilitation of the relationships between collaborators and colleagues leads to more successful science.

An important task of science project managers is to support creative thinking within the project team and manage the team's generation of new knowledge (Ernø-Kjølhede, 2000). Professional project managers deal with a project from its initialisation to the final report. As in all projects, polar science projects involve various phases, milestones and work packages including considerations of resources, community and network management, and risk assessment. Often project managers also serve as community managers since they act as "knowledge translators" to facilitate processes that allow the project participants to communicate their research (ErnøKnølhede, 2000).

The current literature available on project management in polar sciences is sparse. However, the specifics of implementing scientific projects in polar regions have been largely presented in a summary report devoted to the International Polar Year (IPY) 2007-2008 (ICSU and WMO, 2011). This report discusses the importance of international collaborations and interdisciplinarity in polar sciences with regard to the success of large infrastructure projects carried out as international collaborative scientific efforts. The general overview of polar project management with regard to the Arctic has extensively been discussed by the International Network for Terrestrial Research and Monitoring in the Arctic (INTERACT) (INTERACT, 2014). Here, the authors provide constructive examples of Arctic research infrastructures management when it comes to planning, policies, permit issues, environmental impact, staff, marketing, and risks acknowledgements. Despite the theme of polar expeditions being nearly absent from project management literature (Kloppenborg and Opfer, 2002), the history of polar expeditions may offer good learning opportunities as these have been managed with a high level of uncertainty (Aubry and Lièvre, 2018).

This paper addresses the growing community of professional science project and community managers in polar sciences. It describes the basic challenges of polar science project management identified through survey responses in addition to the authors' own various professional project and community management experiences. The four overarching, most challenging themes in polar science project management have been identified: international cooperation, interdisciplinarity, infrastructure, and community management. The paper may also be of interest for scientists working in polar regions, polar research station managers, and other operators active in the field of polar sciences, as well as for national and international funding agencies which face the constant challenge of responsible solutions to support costly international and interdisciplinary polar science projects. 


\section{Examples of Project and Community Management in Polar Research}

International collaborations in polar research have a longstanding history (Barr and Lüdecke, 2010; Gerson, 1958). Inspired by Karl Weyprecht who maintained that polar expeditions should be driven by scientific research, the first International Polar Year (IPY) took place from 1882 to 1883 when eleven countries were involved in 15 polar expeditions. The "magnetic, auroral and meteorological observations at a network of stations in the Arctic and Antarctic" during the second IPY from 1932 to 1933 were considered to "materially advance present knowledge and understanding" (Barr and Lüdecke, 2010; Cannegieter, 1963). Later renamed the International Geophysical Year (IGY), the third IPY (19571958) that also involved globally relevant research, led to the formation of the Scientific Committee on Antarctic Research (SCAR) and the signing of the Antarctic Treaty (Antarctic Treaty, 1959). Applying new tools and technologies to observe polar systems through more than 200 projects, researchers from sixty countries and numerous scientific disciplines were brought together for the fourth IPY from 2008 to 2009 (http://www.ipy.org, last access: 23 April 2019), to make research more efficient through encouragement of international collaboration supporting increased connectivity and leveraging infrastructure.

Furthermore, polar organisations such as the European Polar Board (EPB), the Asian Forum for Polar Sciences (AFoPS), and the Reunión de Administradores de Programas Antárticos Latinoamericanos (RAPAL) in Latin America strive to increase coordination across nations and provide a contact point for the polar communities in certain regions.

In the following section, case studies are provided of how campaigns and expeditions but also research infrastructures have been managed successfully by applying processes and tools of project and/or community management. Each of the cases is briefly described followed by a short outline of the issues that came up and how management of these was put into place to address them. For brevity, we have only included a few good practice examples here. However, there are many more available in polar research, such as e.g., N-ICE2015, or the upcoming MOSAiC drift experiment.

\subsection{The Year of Polar Prediction - International Effort to Improve Weather and Sea Ice Forecasts in Polar Regions}

As a legacy of the last IPY and The Observing System Research and Predictability Experiment (THORPEX), the World Meteorological Organization has initiated the ten-year long Polar Prediction Project (PPP) and its key component, the international Year of Polar Prediction (YOPP), to close current gaps in polar forecasting capacity, eventually leading to more reliable weather and sea-ice forecasts in polar regions. During the core period of YOPP (2017-2019), scien- tists and operational forecasting centres from various countries have worked together to take additional observations which feed into model development to improve polar environmental forecasts with implications to improved environmental safety in the Arctic and Antarctic. Similar to previous IPYs, YOPP aims to bring together various communities; however, by going beyond academia, YOPP also reaches out to operational forecast centres and stakeholders who are using improved weather and sea-ice forecast in their daily operations.

Working on a high international, interdisciplinary, and collaborative level, YOPP is a highly complex project (Werner et al., 2017) which provides an excellent example of how to make use of the various project management tools from the very start of the project, including a continuous review and adjustment over the project's duration. PPP has been scheduled in three phases to prepare (2013-2017), carry out (2017-2019) and consolidate (2019-2022) the research activities of the Year of Polar Prediction. Supported by the International Coordination Office for Polar Prediction, the PPP Steering Group (SG), representing both the observational and the research communities, is central for the project management of YOPP. The SG meets annually to oversee the project's progress, and coordinate and revise the project's development. In the YOPP Implementation Plan (PPP-SG, 2016), the SG provides guidance on the objectives, the project plan, the time schedule, linkages and stakeholder involvement relevant to the various YOPP activities. To date (March, 2019), the YOPP Implementation Plan is revised by the SG for the third time to allow for adjustments with respect to the upcoming Consolidation Phase.

To facilitate coordination and interdisciplinary collaborative work within YOPP, projects, programmes and initiatives but also organisations and institutions who contribute to the aims of the Year of Polar Prediction can request YOPP endorsement by the SG (PPP-SG, 2016). The YOPP endorsement allows for increased visibility of the various YOPP research activities but also provides an international framework for the research carried out within YOPP, with the potential to leverage funding. The endorsement process also enables the SG and the coordinating office to gain an overview about the different activities that they need to oversee - i.e., the endorsement has become a key element of managing the project.

To ensure roles and responsibilities are shared among the Steering Group but also involving the wider YOPP community including early career scientists, dedicated YOPP task teams have been formed to enhance certain activities during YOPP (e.g., sea-ice prediction, processes, evaluation, communication).

Coordination through communication is key for YOPP to engage with everyone involved with YOPP, including the wider community and users of polar forecasts. Communication tools such as the YOPP Explorer and a data portal have been developed allowing the community to fol- 
low the ongoing activities and work with the data produced during YOPP. By organizing science meetings (e.g., YOPP Summit in 2015; Polar Prediction Workshop in 2017, YOPP Arctic Science Workshop in 2019), YOPP facilitates networking and dialogue across boundaries between the YOPP community. With regular contributions by providers and users of environmental polar forecast, the platform "Polar Prediction Matters" (https://blogs.helmholtz.de/ polarpredictionmatters/, last access: 6 March 2019) enables the dialogue between stakeholders.

\subsection{The TRANSSIZ Cruise - Example for Interdisciplinary Research in the Arctic}

The Arctic in Rapid Transition (ART) network organized the expedition "Transitions in the Arctic Seasonal Sea Ice Zone" (TRANSSIZ, see also ARK XXIX/1 or PS92, grant number AWI_PS92_00) as an interdisciplinary field campaign of international early career scientists (Peeken, 2015). It aimed at conducting ecological and biogeochemical early-spring process studies north of $81^{\circ} \mathrm{N}$, along two shelf-to-basin transects of the European Arctic margin, linking past to present sea-ice transitions to further improve the understanding of ecosystem functioning and biogeochemical cycles during the transition from spring to summer. The cruise aboard the German research icebreaker RV Polarstern took place for six weeks in May and June 2015. It involved 51 scientists from eleven countries in collaboration with various international research groups (Peeken, 2016). By comparing data from the shelf, across the shelf-break, and into the deep basin, the cruise participants carried out process studies at sea-ice stations but also in the marginal ice zone (for details see Peeken, 2016).

Scientists were organized in various research teams such as oceanography, sea-ice physics, benthos ecology, trace gases, sea-ice biology, geochemistry, ecosystem, geology and paleoceanography. Good access to information and effective communication of decision was critical during the TRANSSIZ cruise where the chief scientist took over the role of a project manager who not only prepared well in advance of the cruise but also needed to make rapid and sovereign decisions aboard to not stretch station time unnecessarily.

Heavy sea-ice conditions during the Arctic spring season were one of the major logistic challenges during TRANSSIZ. While some of the targeted areas could not be reached due to unexpectedly severe sea-ice conditions, major research goals of individual research groups were met due to a common willingness to compromise to successfully conduct interdisciplinary work. Contamination of samples was another issue. To avoid contamination of the water column by deep sea sediments when bringing sediment cores aboard, a chronological order of sampling casts was determined prior to each work station so that geological sampling was carried out after the sampling of water and sediment trap work had been finished. For some groups, drifting during sea-ice stations appeared to be a problem while other groups were explicitly interested in studying e.g., the organic-matter export under the ice while drifting during $36 \mathrm{~h}$ process studies. Due to strong winds, the vessel leaning against the sea ice drifted for several nautical miles, and, in particular at a slope position, the water depth changed during the duration of the station as much as $400 \mathrm{~m}$. As a result, comparability between samples taken during the first and last casts of the station were regarded difficult. To overcome this problem, extra time was added by the chief scientist to allow relocating the vessel after the process studies were finished. Additional sampling could then be performed so that research groups were able to sample a congruent data set from the water column to the sediments.

\subsection{Ny Ålesund International Research Village}

Ny Ålesund is the northernmost permanent research station on the high-Arctic Norwegian Archipelago Svalbard (Fig. 1). Formerly a coal mining town, its primary activity has now shifted towards research. More than ten international institutions carry out long-term research in Ny Ålesund and its vicinity. The Norwegian Polar Institute (NPI) coordinates the international research activities while the infrastructure is managed by the Kings Bay Company, which provides the basic infrastructural support (e.g., flights, harbour, accommodation and board), as well as access to common research facilities like laboratories and boats. Despite the highlatitude location, the well-developed infrastructure, relatively easy year-around access and the proximity to field sites have made Ny Ålesund a popular destination for numerous international and interdisciplinary research projects over the past few decades.

In a place like Ny Ålesund, where hundreds of research projects are conducted on a regular basis, the coordination of research and infrastructure facilities is a challenge. Coordination of research and the use of infrastructure on Svalbard is overseen by the Svalbard Science Forum (SSF). SSF is coordinated by the Research Council of Norway (RCN), which runs a SSF secretariat in Longyearbyen. All research and monitoring projects conducted on Svalbard have to be registered in the Research in Svalbard (RiS) database, a portal managed by SSF, which contains information about more than 3500 projects (as of February, 2019). In addition, the Svalbard Integrated Arctic Earth Observing System (SIOS) has been established as a regional observing system which aims to strengthen cooperation between researchers in Svalbard and improve access to data and results. As an international infrastructure project initially supported by the EU (FP7 programme) and later by RCN and other partners, SIOS has entered the operational phase in 2018. The SIOS Knowledge Centre established in Longyearbyen is intended to provide better-coordinated research services and access to observations, data, logistics, education, research laboratories and research results, thus contributing to increased knowl- 


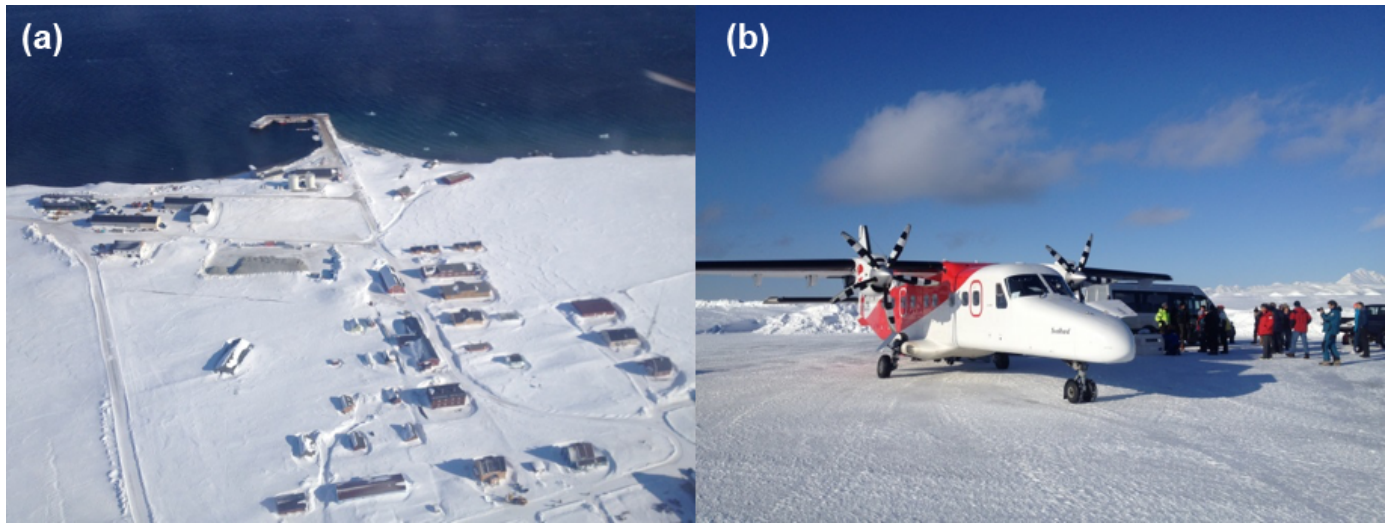

Figure 1. View on Ny Ålesund from a plane (a) and a small airplane on airstrip of Ny Ålesund (b). Credits: Alexey Pavlov (Norwegian Polar Institute).

edge and promotion of research and research infrastructure cooperation in Svalbard.

Since its establishment in 1994, the Ny Ålesund Science Managers Committee (NySMAC) has facilitated cooperation and coordination of research and monitoring activities in $\mathrm{Ny}$ Ålesund. NySMAC promotes the four flagship programmes (atmosphere, terrestrial ecosystem, Kongsfjorden ecosystem, glaciology), which aim to bring together researchers in the different disciplines to increase collaboration through e.g., field campaigns or publications with the goal of increasing research quality. NySMAC includes representatives from 18 international member institutes and three observer institutions. The NySMAC secretariat is located at NPI in Troms $\varnothing$.

Funding availability, or the lack thereof, is among the major challenges when it comes to infrastructure access and logistics in both Arctic and Antarctica. With an already welldeveloped infrastructure on Svalbard, this challenge is at least partly tackled successfully via regular financial support for infrastructure access provided by the RCN via the SSF's Arctic Field Grants and Svalbard Strategic Grants. Both SIOS and the EU-funded project "International Network for Terrestrial Research and Monitoring in the Arctic" (INTERACT) also regularly provide funding for transnational access to stations on Svalbard.

\subsection{National Infrastructures}

\section{Khibiny station}

Khibiny research and educational station located on the Kola Peninsula, Murmansk region, Russia, is managed by the Lomonosov Moscow State University (LMSU). It was established in 1948 and operates year-round with four research scientists as station staff hosting visiting research groups and student training practices - up to eighty people at a time. The station's infrastructure includes a student dormitory with lecture room, laboratory, and dining room, and a main ad- ministrative building with several apartments for visiting researchers.

Institutional access to the station is limited by the agreements with the owner LMSU, which is advantageous in most cases for international cooperation. Official institutional support to access the station may, however, be limited due to the growing number of private logistics operators who also provide support for research groups coming to the region. Similar to Ny Ålesund, Khibiny station is also part of the International Network for Terrestrial Research and Monitoring in the Arctic (INTERACT) which provides access to the station's research facilities.

As for nearly all fieldwork stations hosting international research groups, different requirements of research and sampling procedures demand for individual flexibility of Khibiny station's personnel and ad-lib approach when working in the Russian Arctic. Challenges can occur because of language barriers, cultural differences, and different levels of professional flexibility and responses to critical emergencies. Furthermore, challenges at the institutional level such as differences in financial practices and mechanisms, lack of personnel (especially field assistants and technicians), or a high level of bureaucracy within state institutions and federal services may exist. The latter can dramatically affect the ability to conduct in-situ research and field expeditions when visa processing procedures, permission processing on import and/or export of research equipment and samples are involved.

Since Khibiny research station is located in mountainous terrain, it bears an additional risk typical for cold environments. The station has therefore implemented particular risk management practices and emergency training lectures that the station manager provides to visitors before going in the field. 


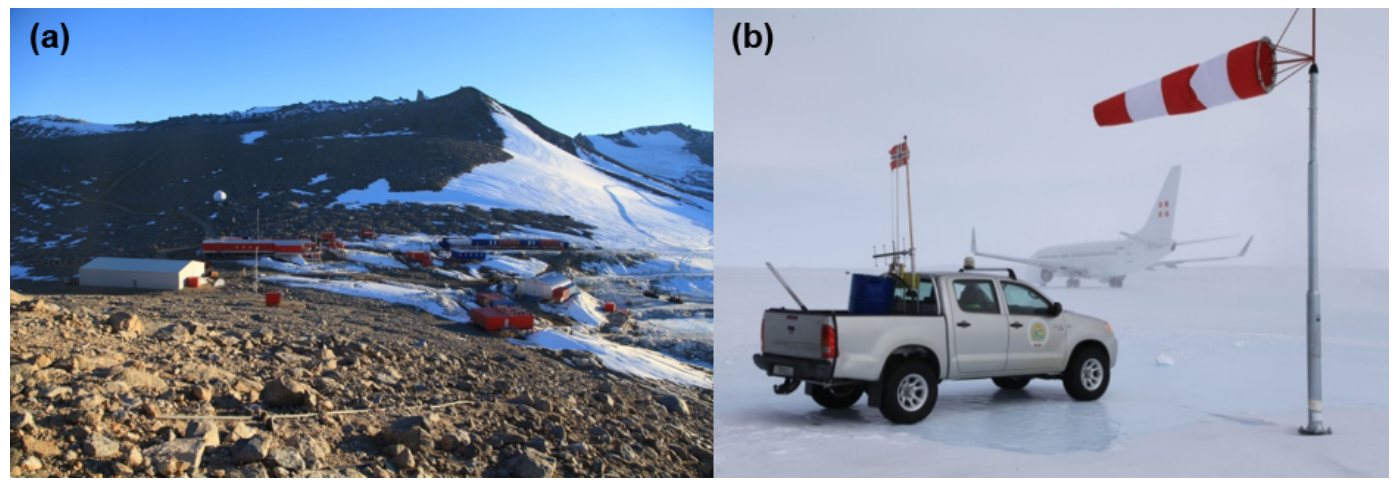

Figure 2. Troll Station (a) and Troll airfield (b) with a parked Boeing 737 aircraft. Credits: Sven Lidström (Norwegian Polar Institute).

\section{Troll Station}

Troll Station is a year-round research station in Dronning Maud Land, Antarctica operated by the Norwegian Polar Institute (NPI) (Fig. 2). Good bandwidth to enable remotely monitored and controlled projects and easy access for onsite work with adaptive transport solutions have been identified by NPI as key factors to enable research at Troll station but also to save time and costs, especially when only several days or weeks are needed to conduct actual field work.

Therefore, the Troll Airfield runway was constructed in 2005 on the blue ice close to the station (Fig. 2). The airfield has been successfully operated during the Antarctic summer seasons (November to March) and meets the requirements even of modern commercial long-range aircraft such as Airbus 319 or Boeing 737 and 757. An airfield with the capability of adapting to a wide range of aircraft allows for customized transport solutions which is a great advantage to scientists and technical personnel. Flight time from Cape Town, South Africa to Troll Station is only about six hours, and a couple of flights are carried out each season between Norway and Troll Station, with the fastest flight time so far being $24 \mathrm{~h}$. Since Troll airfield is one of the few intercontinental airfields in Antarctica, it has become an important base for international airborne research.

High bandwidth was another area that NPI identified as vital in enabling tomorrow's research. At most stations in Antarctica, bandwidth is still limited and sometimes only accessible for part of the day. Due to a collaboration with the Norwegian company Kongsberg Satellite Services, perpetual data transfer at Troll station can now occur in the scale of gigabyte. While there is always a station research engineer present in case operations need human intervention, the new data transfer facilities have enabled scientists to also remotely connect and control their instruments.

The daily life at a polar research station is similar in the Arctic or the Antarctic. A normal day starts with a meeting where the different needs are coordinated. The station manager needs to make sure the station is fully functional with power, water, communications and other equipment needed by scientists, technicians or engineers who are more in the role of customers or visitors. Nevertheless, a visiting scientist can also have the role of a project manager who interacts with the stations manager in order get station support for their project. For smaller projects, the scientist can thus also act as a project manager. For larger and more complex projects that require much support, project management to plan field work at a research station quickly becomes a fulltime task. Shipping of equipment, pre-deployment training, and making sure that equipment, personnel support, power and communications requirements can be met are key in the planning process because once being at the station or in the field, there is little time to compensate poor preparations.

\section{Methodology}

In addition to selected case studies chosen as examples of project and community management efforts (Sect. 2), a community survey was carried out to better understand current challenges and opportunities of polar science project and community management. Results of the survey were evaluated to present them in this paper.

A structured questionnaire was developed to learn about the expertise and knowledge required by project and community management professionals as well as the most common challenges they face when implementing their projects. The survey entitled "Project Management and Community Management in Polar Sciences: Challenges and Opportunities" contained 29 questions divided into eight chapters: General information (with basic statistical overview of respondents, examination of levels of authority in project management) and different challenges in project and community management (importance of diverse components). The survey contained open-ended and closed-ended multiple choice questions where respondents were given a range of responses to choose from (Table 1). The survey was launched online through Google forms service and remained open for 31 days; it was disseminated through different network e- 
Table 1. Examples of questions in the developed survey.

\begin{tabular}{ll}
\hline Question & Answer \\
\hline $\begin{array}{ll}\text { Question 8 - What is your authority level within } \\
\text { your projects? }\end{array}$ & - I can take decisions for my project \\
& - I can recommend/advise on decisions \\
& - I don't have decisional power/influence \\
& - Other (please specify) \\
\hline Question 10 - (International) cooperation: & [1- Not challenging ... 5 - Very challenging] \\
$\begin{array}{ll}\text { Please rate (from 1 to 5) the following } \\
\text { challenges. If nothing applies, please choose }\end{array}$ & - Cultural differences \\
NA & - Funding \\
& - Different national strategies/political context \\
\hline $\begin{array}{l}\text { Question 12-a - What else (in addition to above } \\
\text { question) is the most challenging for you in }\end{array}$ & [open-ended] \\
infrastructure/logistics?
\end{tabular}

mailing listservs (e.g., Cryolist, ArcticInfo, IASC, Polar Prediction Project) and via direct individual emails.

Survey questions, within the different proposed themes - international cooperation, interdisciplinarity, infrastructure/logistics, community management, risk management, and time management - were structured around the same survey logic for each theme to maintain comparability between the results of different themes. An ethical protocol was followed, with the survey supported by privacy and impact statements proclaiming no negative outcomes for the respondents. Individual responses were collected via Google Drive. These will remain confidential, while the results presented in this paper are shared and analysed anonymously in a generalized manner.

\section{Target Group}

Survey research is defined as "the collection of information from a sample of individuals through their responses to questions" (Check and Schutt, 2012). Community and project managers in polar regions were the primary target group of survey respondents. However, the survey was open to anyone playing an active role in polar science projects. The total number of responses provided by the community during the campaign was $n=284$. More than half of the respondents $(51.8 \%)$ defined themselves in the role of professional project managers, while $2.5 \%$ defined themselves as professional community managers, and $15.8 \%$ as both. A large pool of remaining responses $(29.9 \%)$ referred to different roles in science projects (from principal investigator to project data manager and operations coordinator) with all of them being relevant to project management at different levels (Fig. 3).

Additional questions in the first part of the survey ("General information") were developed to obtain a statistical overview of the group of respondents by multiple-choice op-
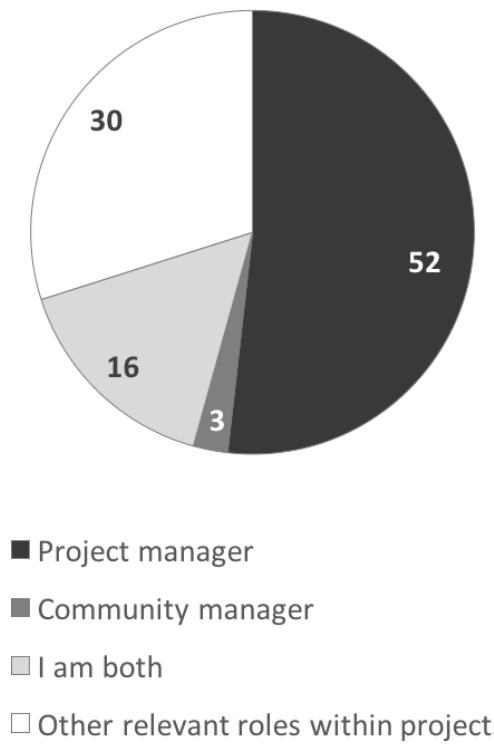

Figure 3. Distribution of roles in project management (PM) and community management $(\mathrm{CM})$ within the group of respondents.

tions. The results showed that among the 284 respondents, ca $63 \%$ were working in project or community management in the Arctic or in Antarctica, respectively, including those working in both regions. Management in High Mountain terrains was the focus of $34(12 \%)$ respondents. A question regarding the project specialization (What type of projects are you most involved with?) allowed participants to choose between expeditions, research, network coordination, logistics, and data management (Fig. 4a). As a result, management of research projects (249 respondents, $87.7 \%$ ) was the most common category, while other had less representation among the survey group (Fig. 4a). Such results were linked with the responses to a question about the professional affiliation (What type of organisation do you work in?); 225 


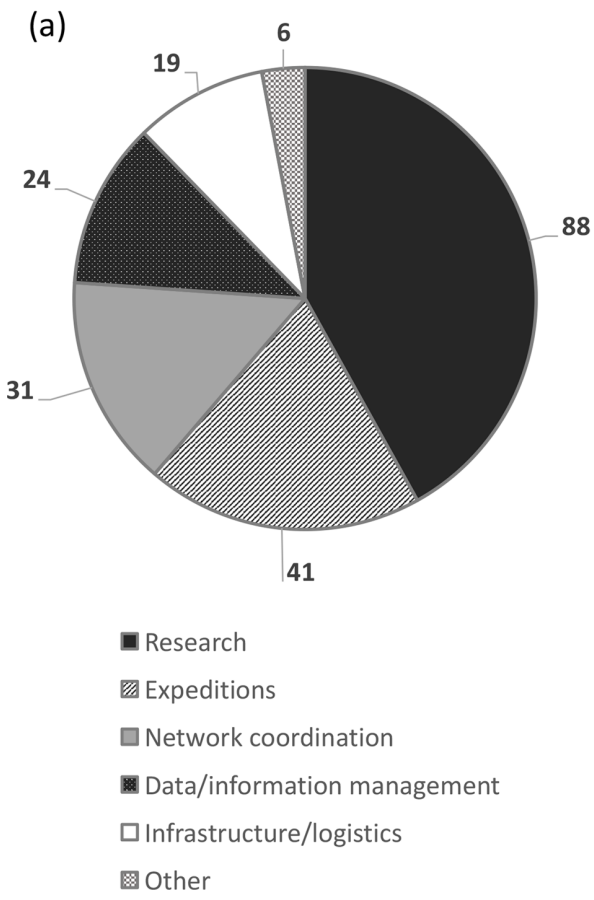

(b)

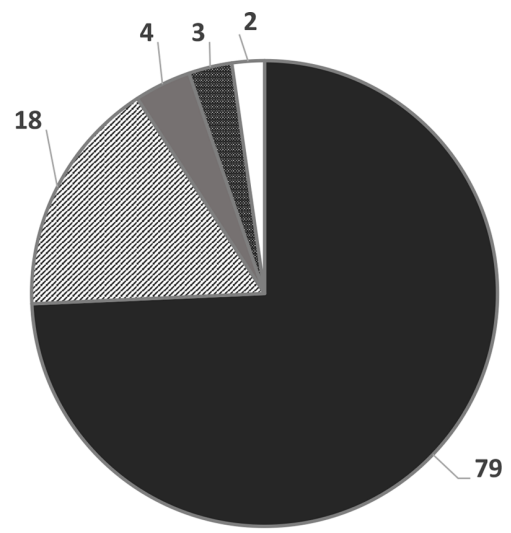

- Research institute/University

四 Government

Private

조을 /non-profit

$\square$ Other

Figure 4. Distribution of project (a) and organization (b) types among respondents group.

$(79.2 \%)$ respondents were connected to research institutions or universities (Fig. 4b).

The question (Where are you based?) revealed that $56.3 \%$ of respondents were from Europe, $23.9 \%$ were from North America, $8.1 \%$ of the respondents were from Asia, $6.3 \%$ were either based in South America or Australia/New Zealand, and $0.4 \%$ (one person) were from Africa.

\section{Survey Results}

Question Q9 in the survey addressed the general challenges in polar sciences project management: What is important when planning a project in polar sciences? Survey respondents considered the following aspects important: international cooperation, the interdisciplinary nature of polar sciences, infrastructure/logistics (including risk management) (Fig. 5). Differences occurred in the rating of survey respondents who considered themselves as professional project and community managers $(\mathrm{PM} / \mathrm{CM})$ versus those in other roles within polar science projects (OR). While OR rated all other points (e.g., international cooperation, infrastructure access, logistics, see Fig. 5) less often as "very important" than $\mathrm{PM} / \mathrm{CM}$, the interdisciplinary nature of polar sciences was rated higher by OR (42\%) than by PM/CM (38\%).

\subsection{International Collaboration}

In Q10 of the survey, participants were asked to rate the following five challenges with respect to the topic "international cooperation": cultural differences, communication barriers, funding, differing national strategies/political context. The scale provided was 1 to 5 , with 5 being "Very challenging". A majority of the participants (48\%) selected "Funding" as the most challenging aspect of international collaborations, followed by "Differing national strategies and political contexts" (23\%, Fig. 6). These results corresponded with the responses to the open-ended question posed "What else (in addition to above question) is most challenging for you in international cooperation?" Funding, and specifically the lack of a coordinated international funding mechanism was consistently brought up. Other aspects within international coordination e.g., a mismatch in timetables for funding applications, differences in local and national regulations, differences in reporting requirements, fluctuating currency values, and coordinating between time zones were mentioned by respondents. Another issue noted in the open-ended question were the different national regulations and processes to acquire permits to carry out research in the polar regions.

\subsection{Interdisciplinarity}

In question Q11, survey participants were asked to rate the following challenges with regard to the interdisciplinary nature of polar sciences: funding, scientific agenda, communication, planning, infrastructure and logistics, team management, and discipline-specific culture. Most survey participants $(43 \%)$ rated "Funding" with " 5 - Very challenging"; "Infrastructure and Logistics" and "Planning" followed with $23 \%$ and $18 \%$, respectively (Fig. 7). Project and com- 


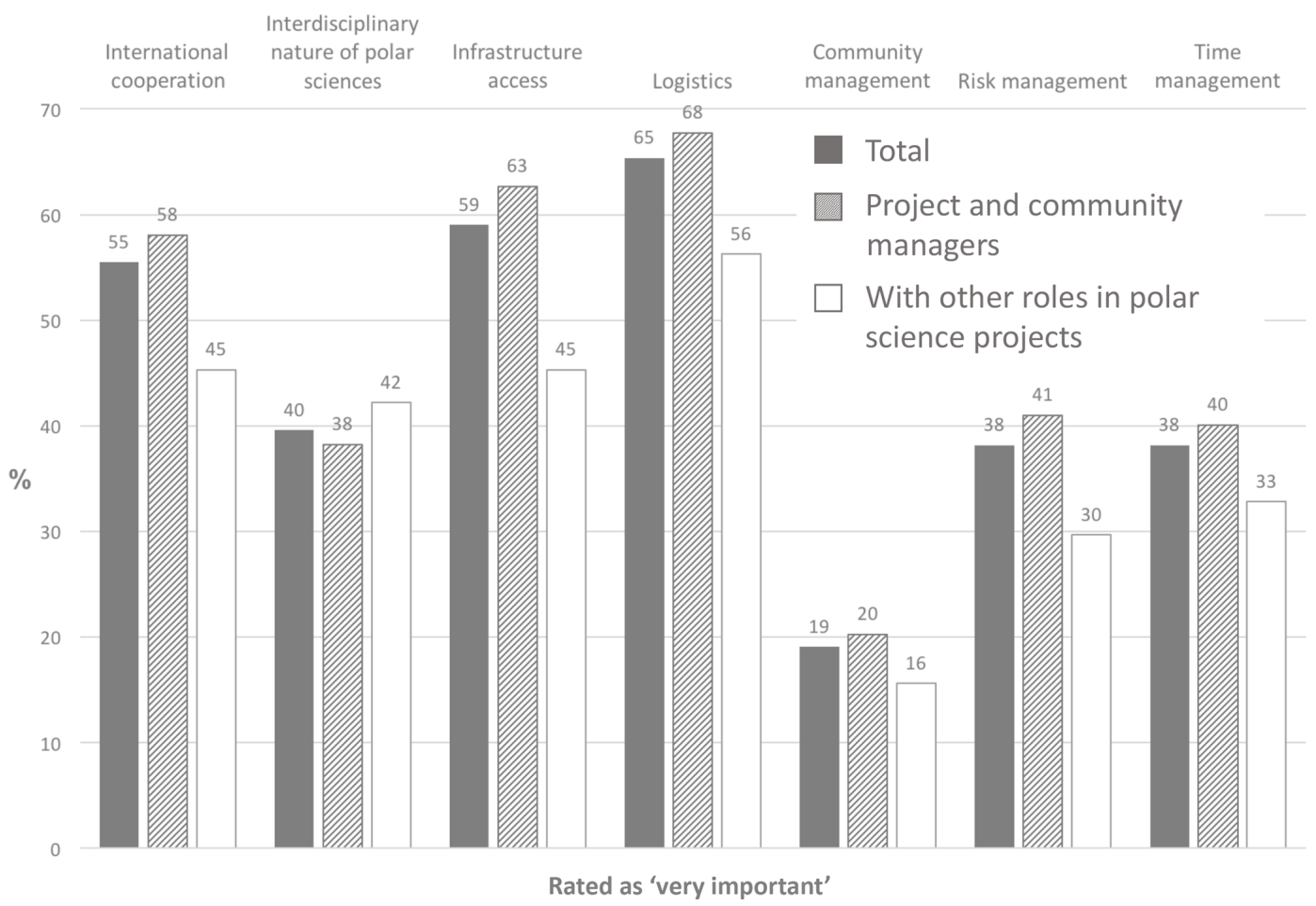

Figure 5. Important in polar science projects: Survey respondents (\%) rating as "5 - very important" when asked the question Q9: Please rate (from 1 to 5) the importance of the following points for you when planning a project in polar sciences?.

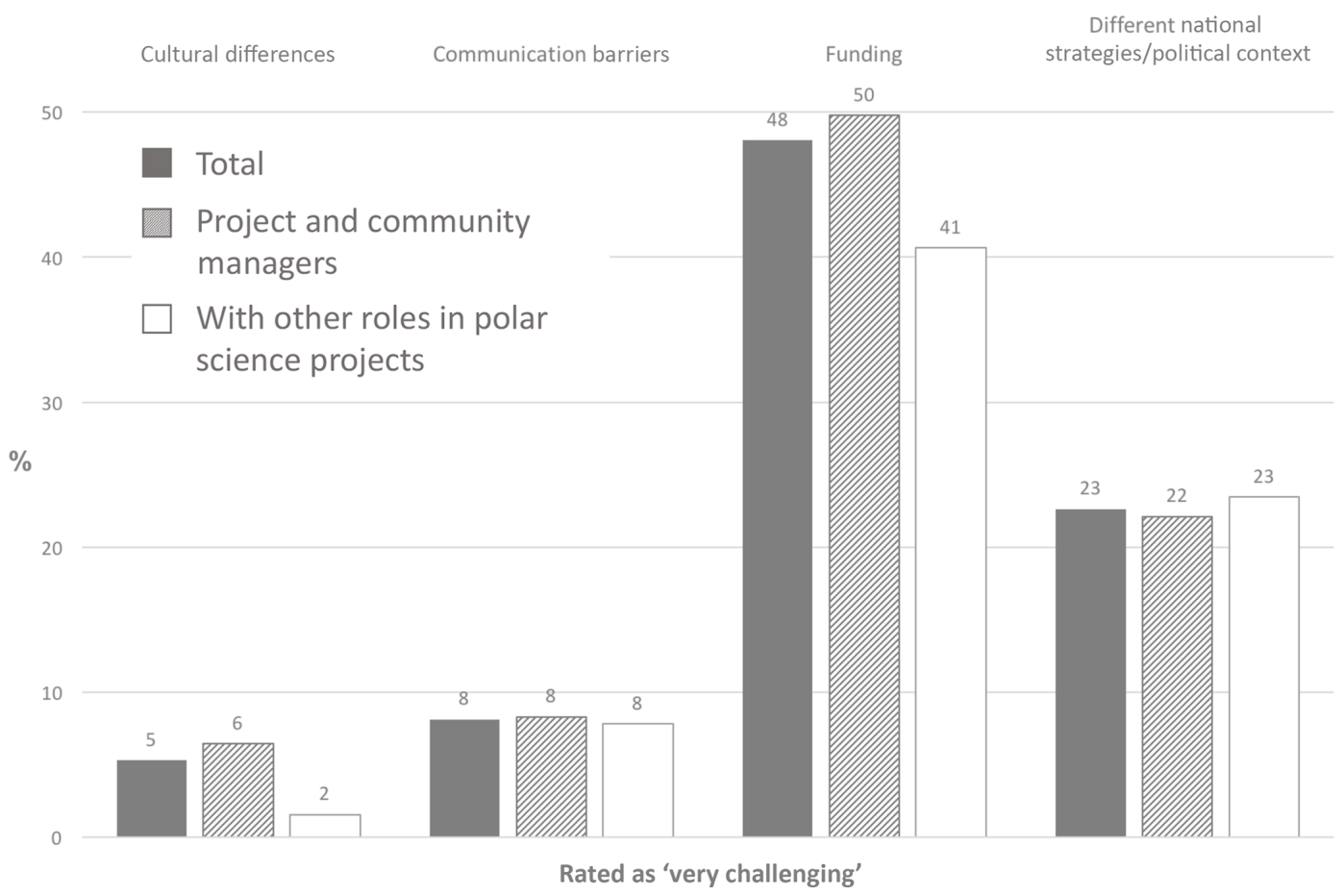

Figure 6. Challenges associated with international cooperation in polar science projects. Survey respondents (\%) rating as " 5 - very challenging" when asked the question Q10: 10. (International) cooperation: Please rate (from 1 to 5) the following challenges. 


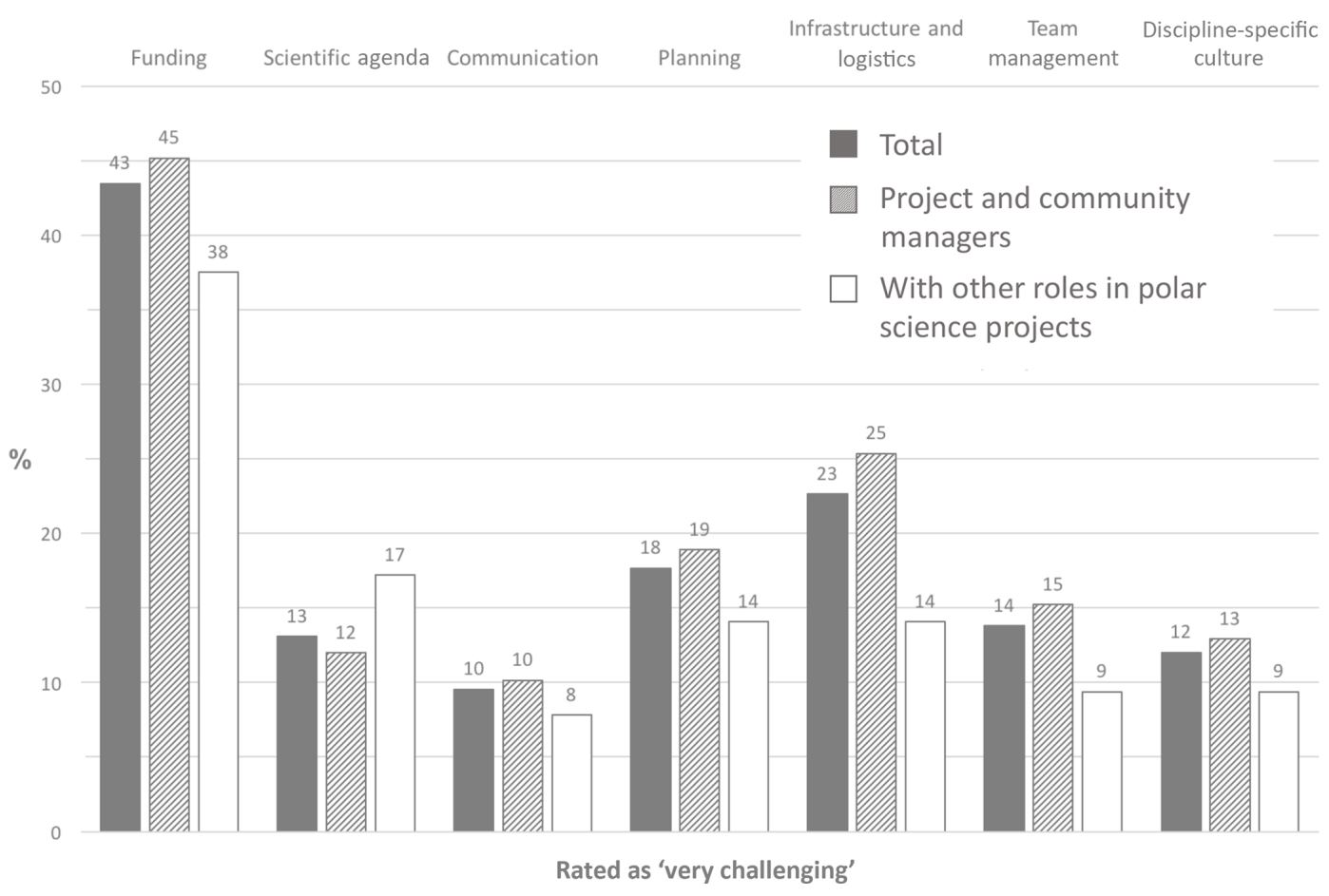

Figure 7. Challenges associated with interdisciplinary work in polar science projects. Survey respondents (\%) rating as " 5 - very challenging" when asked the question Q11: Interdisciplinary nature of polar sciences: Please rate (from 1 to 5) the following challenges.

munity managers more often evaluated "funding" issues as "very challenging" ( $45 \%)$ compared to those respondents with other roles in projects $(38 \%)$. Results concurred with additional comments some of the survey participants provided in Q11a ("What else (in addition to above question) is most challenging for you in interdisciplinary projects?"), where issues related to financial support for interdisciplinary polar science projects were mentioned. In addition, many of the respondents in the open question emphasized "communication" with regard to discipline-specific language and terminology, as well as challenging issues related to personal relationships. The challenge of a "scientific agenda" was rated higher by those with other roles in projects (17\%) compared to survey respondents considering themselves as project and community managers (12\%) (Fig. 7).

\subsection{Infrastructure}

Infrastructure access and logistics were considered by most survey respondents (59\% and $65 \%$ respectively) very important when planning a project in polar sciences (Fig. 5). With the interdisciplinary nature of polar sciences, the category on "Infrastructure and logistics" was the second most important challenge ( $23 \%$ of respondents ranked it as very challenging) after "Funding" (43\%) (Fig. 7). Under the question (Q16) about risk management in polar projects, categories "Operations" and "Technical" were also ranked the most challeng- ing (Fig. 8), which reflects the peculiarities of operations in what are often unpredictable environmental conditions.

Survey responses on challenges of infrastructure and logistics (Q12; Fig. 9) revealed that "Funding" was mentioned here as the most challenging factor $(47 \%)$, followed by the categories "Operations in extreme environments" (31\%), "Technical uncertainties" (26\%), "Health and safety" (20\%), "Data access and management" (17\%), and "Communication/connectivity" (15\%).

\subsection{Community Engagement}

Community engagement is an important aspect of project management and the principal task of community managers. Out of the 284 survey respondents, seven identified themselves solely as community managers, one identified as a community manager and scientist, and 45 respondents considered themselves as both community and project managers (Fig. 3). Funding was identified as the largest challenge in community management (40\%, Fig. 10). Amongst other aspects identified as "very challenging" in community engagement, stakeholder engagement was selected by $20 \%$ of respondents. As building and extending a scientific community requires funding and other resources, community and particularly stakeholder engagement is at least partly also a funding issue. While stakeholder engagement might be central to community managers, it is just one of many tasks of project managers. Comments across community manager re- 


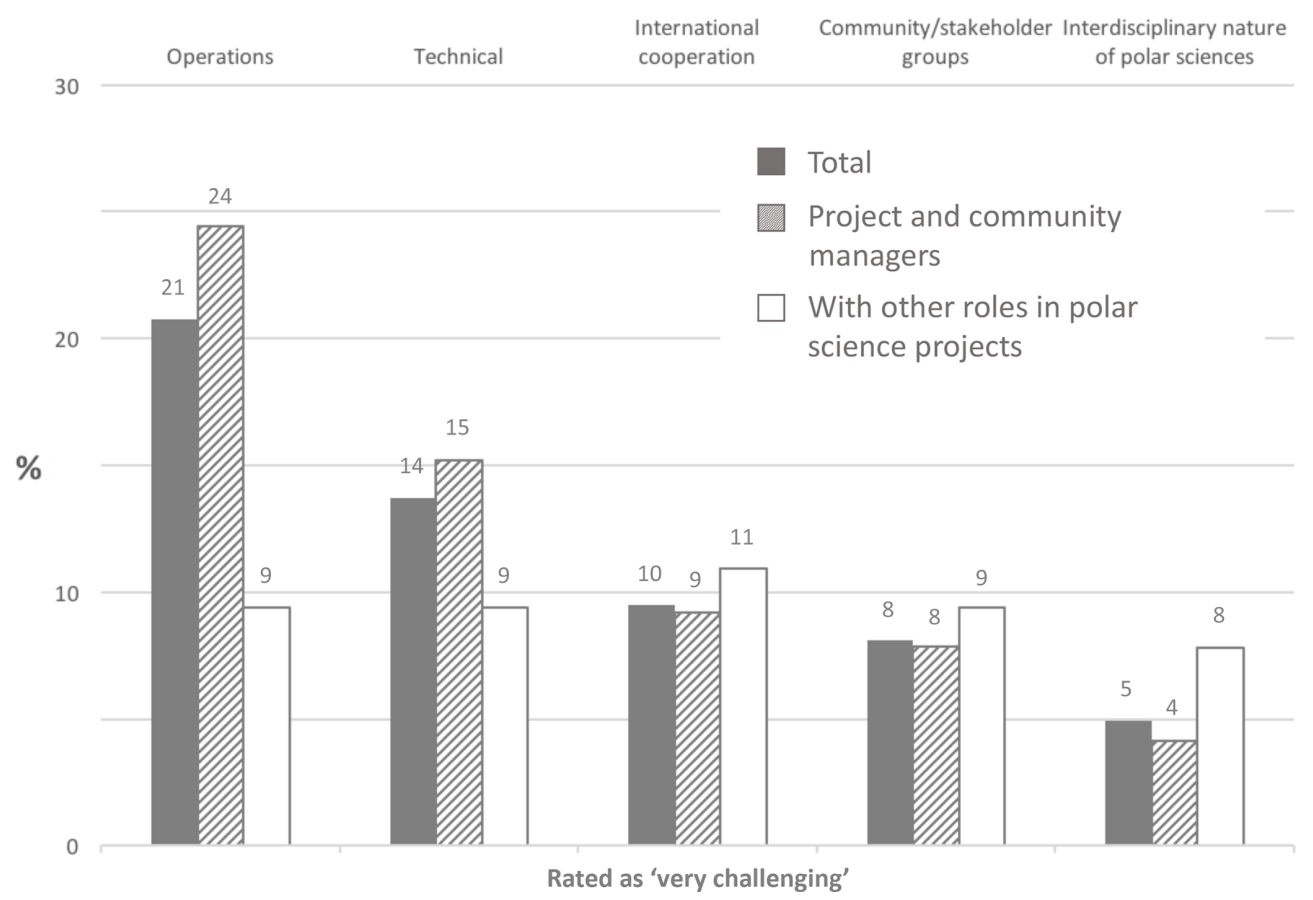

Figure 8. Challenges associated with risk management in polar science projects. Survey respondents (\%) rating as " $5-$ very challenging" when asked the questions Q16: Risk management: Please rate (from 1 to 5) the following challenges.

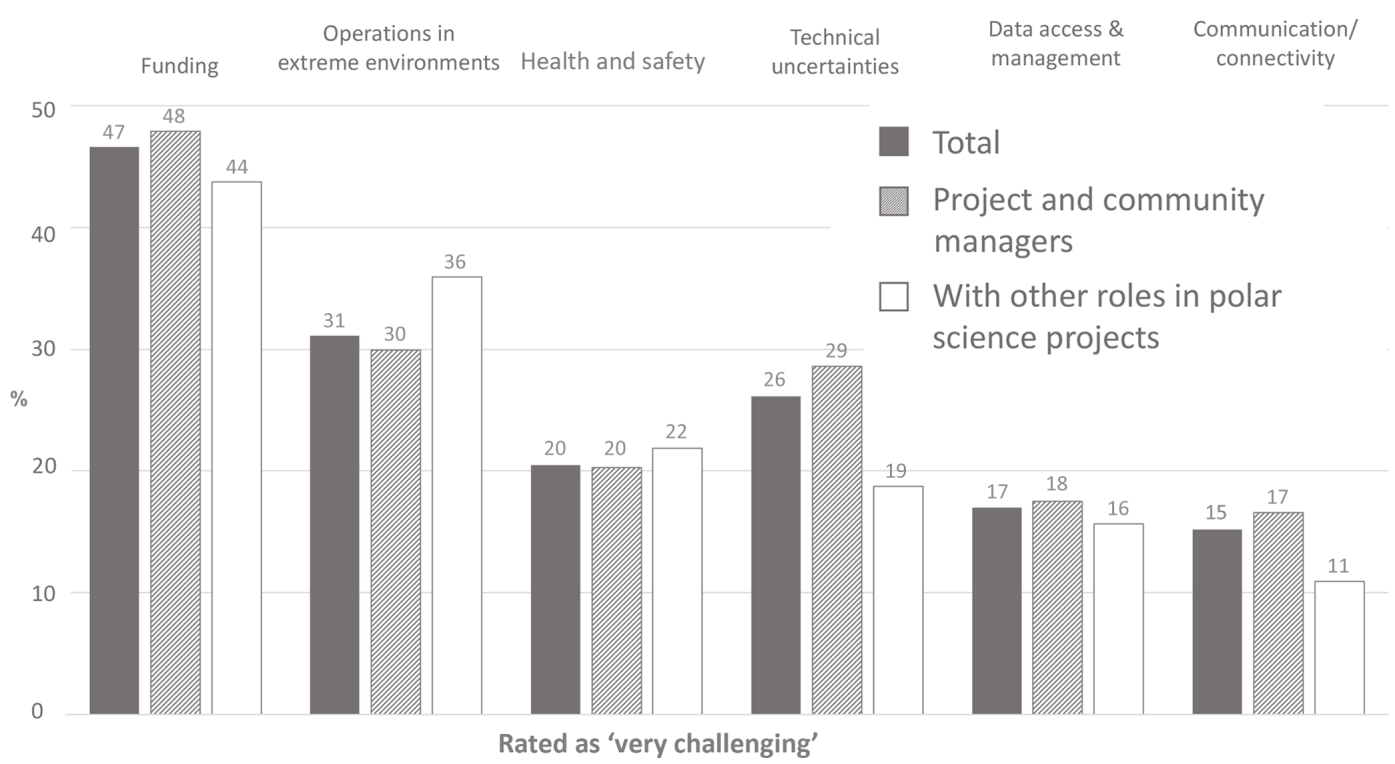

Figure 9. Challenges associated with infrastructure and logistics. Survey respondents (\%) rating as "5 - very challenging" when asked the questions Q12: Infrastructure/logistics: Please rate (from 1 to 5) the following challenges.

spondents to the open-ended question clearly indicated that no matter the challenges, community engagement is seen to be critical in service of advancing scientific aims.

\section{Discussion}

In the following, we address four overarching themes in polar science project management - international collaboration, interdisciplinarity, infrastructure and logistics, and community engagement - using the survey results (Sect. 4) as well as case studies (Sect. 2) to identify the most important chal- 


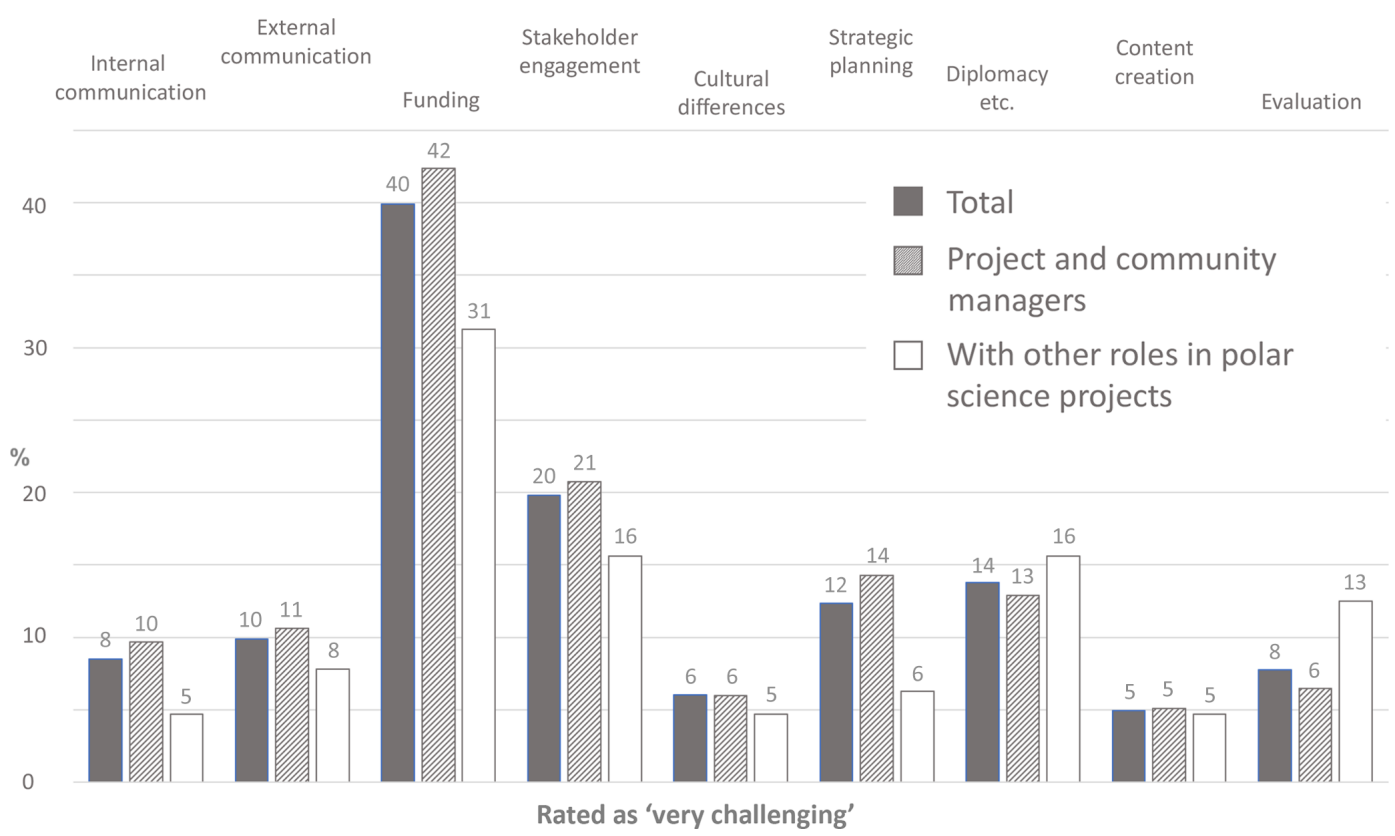

Figure 10. Challenges associated with Community Engagement. Survey respondents (\%) rating as "5 - very challenging" when asked the questions Q14: Community: Please rate (from 1 to 5) the following challenges.

lenges within these themes and provide recommendations for each of them.

\subsection{International Collaboration}

Polar research is considered inherently collaborative due to logistical challenges involved in working in polar regions. Complexities of research questions and the high costs involved for equipment, analytical tools, and labour further increase the need for international collaboration in both polar regions (see also Sect. 5.3). The governing treaty for the continent of Antarctica and the International Polar Years are great examples of how international collaboration for scientific achievement and benefit to humankind were put ahead of the gains of individual nations (Antarctic Treaty, 1959; Barr and Lüdecke, 2010). Such large international collaborative efforts also provide a great opportunity for nations relatively new to polar research to substantially bolster their polar scientific infrastructure. These efforts are also a rationale for ambitious projects that might be difficult to justify on their own (Mervis, 2007).

International collaborations have many benefits for individual researchers, their institutions, and also at the national level. Working within international teams such as the Year of Polar Prediction (Sect. 2.1), researchers gain new networks and skills, while large multi-national projects (e.g., the TRANSSIZ cruise, Sect. 2.2) share the cost of science and logistic capabilities with the knowledge produced benefitting all countries involved (Nath et al., 2016). However, collaborative projects extending across national boundaries also introduce their own set of project management chal- lenges. These challenges begin when individuals from different countries and organizations, with different funding mechanisms, and different value systems share authority, responsibility, and decision-making (Shore and Cross, 2005). A project manager used to work within an international setting will have the required cultural sensibility to convey between diverse team members to positively influence team effectiveness.

Survey respondents clearly specified the issues they face while engaging in international collaborations in polar research, some of which are very similar to those faced in other disciplines. Funding stood out as the major hurdle due to (a) lack of a coordinated funding mechanism; (b) differences in academic and financial calendars, funding applications, and review processes; (c) differing (and oftentimes multiple) reporting requirements for funding; (d) fluctuations in currency exchange rates; and (e) lack of sustained funding sources for long-term collaborative projects. The hurdles mentioned here can only partly be relieved. The main recommendation from this paper is to take them into consideration in the planning process to support truly coordinated funding processes with international partners.

Differences in the national strategies provides yet another barrier, especially in the context of a changing political environment. These include (a) finding a balance between international cooperation and domestic constraints; (b) differing national regulations for field sites; (c) variations in national scientific priorities thus affecting science funding; and (d) differences in safety standards, regulations and requirements. A set of guidelines resolving major issues (as above), 
while specifying international standards would further enhance international collaborations in polar research.

Other issues obstructing further international collaborations in polar research were (a) cultural and language differences; (b) differences in time-zones hampering preparative meetings; (c) differences in permits required and how to obtain them, and other bureaucratic barriers; (d) differences in medical requirements for fieldwork,; and (e) differences in methodologies used. These issues are heightened if the international collaborations are also interdisciplinary, adding yet another layer of complexity.

Some of these barriers have started to be recognised at both poles, and efforts are underway to identify and resolve these issues. In the Arctic, with the signing and ratifying of the Agreement on Enhancing International Arctic Scientific Cooperation (Arctic Council, 2017), topics for furthering scientific cooperation include intellectual property, entry and exit of persons, equipment and material, access to research areas, infrastructure and facilities, and data. Finland, under the auspices of the Arctic Council, was hosting the inaugural meeting in 2018 for the implementation of the Agreement on Enhancing International Arctic Scientific Cooperation which aims to get input from stakeholders on both barriers and opportunities related to this agreement.

In the Antarctic, some of these issues have long been recognised with the Antarctic Treaty (Antarctic Treaty Secretariat, 2019), with the parties to the treaty implementing the Environmental Protocol into domestic legislation in order to establish a clear permitting regime for activities to be carried out by the treaty parties. These permits can be obtained in advance by researchers from the relevant National Competent Authority (Antarctic Treaty Secretariat, 2019). Other organisations like the Committee of Managers of National Antarctic Programs (COMNAP) and the European Polar Board (EPB) have recently started internal activities recognising these barriers to research and looking at ways to overcome them (Miguel Ojeda, personal communication, 2018).

\subsection{Interdisciplinarity}

Since "real-world problems such as climate change do not come in disciplinary-shaped boxes", new approaches require knowledge and understanding across disciplines (Jeffrey, 2003). Integrated studies of coupled human and natural systems allow for new and complex patterns that otherwise would not be identified (Liu et al., 2007). The same is true for integrated work across various different natural science disciplines, in this paper henceforth referred to as interdisciplinary work. While collaboration across science disciplines is challenging, it becomes increasingly important also in various fields of polar sciences; in particular, as it demands scientists to put their specific results into larger perspectives to trigger communication among different groups (Werner et al., 2016). In recent years, interdisciplinary programs may have eventually even become disciplines themselves (e.g., biogeochemistry).

Polar science projects can be viewed as temporary organizations (Lundin and Söderholm, 1995) that largely rely on interdisciplinary team work (see Sect. 2.2). Individuals of this team usually start as a group "with very diverse backgrounds, experiences and expectations regarding the project objectives" but need to become a coherent team as the project progresses (Sydow and Braun, 2018).

The potential for conflicts is high in interdisciplinary project teams. In general, research projects involve various paradoxes, such as the large degree of autonomy versus a need for strict control, or a knowledge asymmetry between the individual researchers who usually have a better knowledge about the potential of their research contributions than their project managers (Ernø-Kjølhede, 2000). In international and interdisciplinary projects such as in polar sciences, work across organizational, disciplinary and national borders adds to the conflict potential (Ernø-Kjølhede, 2000) so that designing a research co-operation with minimised conflict potential (Ernø-Kjølhede, 2000) is key for managing interdisciplinary projects in polar sciences.

Each science discipline involves its own agenda and expertise. Successful interdisciplinary projects require the various team members to appreciate perspectives, terminology, and methods different from their traditional science environments. The National Research Council (2015) mentions the deep-knowledge integration gained through interdisciplinary research as one of the challenges for team science. Here, communication plays a key role. Often, a science community is constrained to its own discipline-specific network. However, effective team management with communication among all team members representing the different disciplines involved in the project is necessary to develop a common language and collective goals, and to plan truly interdisciplinary research activities. A project manager who is able to look at the big picture and continuously fosters dialogue between team members to enable details in planning and implementation can help to overcome potential differences and misconceptions across different science disciplines. This, in particular, is central with regards to the mutual use of the available infrastructure, hereby minimizing logistic efforts.

Management of interdisciplinary science efforts already faces challenges in the initialization of a project. To be successful in funding, all science disciplines involved in a project, including cross-discipline field campaigns, need to be thoroughly explained in a project proposal. While efforts to support interdisciplinary projects have grown in recent years (e.g., EU Horizon 2020 calls), financial support for interdisciplinary projects is still considered challenging as peer reviewers invited to evaluate a proposal for an interdisciplinary science project may still be biased by their own traditional science discipline. However, by demanding a specification about how to integrate disciplinary perspectives and methods throughout the life of a research project 
and by providing guidance for the reviewers' evaluation of collaborative interdisciplinary team plans, funding agencies are in a position to foster an interdisciplinary culture within the scientific community (National Research Council, 2015).

Successful project management to implement interdisciplinary science projects is needed to ensure the coordination of different groups and activities in the field, as well as their work in the lab and at home institutions, involving analysis and interpretation of data. For the evaluation and conclusion of an interdisciplinary project, scientific results will need to be evaluated by all team members for scientific delivery such as in science papers and for a final report to be submitted timely to the funding agency.

\subsection{Infrastructure}

The basic physical and organizational structures and facilities (e.g. buildings, roads, power supplies) needed for scientific research projects in polar regions and high altitude mountain regions often are more complex than the infrastructure serving researchers in other regions. Polar infrastructure has to withstand weather extremes such as prolonged sub-zero temperatures and large seasonal temperature fluctuations, snow and ice, as well as strong wind conditions. Often, adaptations, special design and individual solutions are needed for self-sustained infrastructure in polar regions since access, construction and maintenance of polar research sites are often limited to short summer seasons.

A more established infrastructure exists in the Arctic where people including Indigenous peoples have been present for generations. In contrast, humans have only been present in the Antarctic for slightly more than one hundred years, usually staying only for a limited period of time. Surviving in Antarctica without resupplies would thus be difficult if not impossible. Hence, differences exist in carrying out research projects in the Arctic and in Antarctica. In the Arctic, access is usually easier and regulations depend on national laws. In terms of environmental regulations, the Antarctic Treaty agreements are in many cases stricter than in the Arctic. For example, nuclear power stations are operated in the Arctic, while they are forbidden in Antarctica.

Arctic research has traditionally been limited by access and presence in the region. Only a handful of countries own land in the Arctic or have access to ships with icebreaking capability. One exception is Ny-Ålesund on Svalbard (Sect. 2.3), which is open for scientific research under the Svalbard Treaty (1920). Access to Ny Ålesund is possible by commercial aircraft with several flights per week yearround and occasional boat connection. In contrast, access to Antarctic research stations is more complicated, with very limited infrastructure for transport. Most stations are completely isolated for several months of the year when many of the operations are reduced.

A good understanding of the limits and possibilities of the infrastructure can help to deal with comprehensive logistics requirements to carry out research projects in polar regions. However, not only buildings and equipment are needed but successful and safe operations rely even more on trained and experienced support staff under the challenging Arctic and Antarctic conditions. Running a station and its maintenance in polar conditions often requires special training where involving expertise on the infrastructure early in the planning phase of projects and campaigns has proven important. In addition, station managers need to make decisions quickly while they have to overlook the activities of the station team and visitors.

With the rapidly changing climate, future challenges and requirements of polar research projects may pose new demands on infrastructure, logistical and technical support. Novel opportunities to advance polar research arise with new technologies allowing for new possibilities to access remote locations, with new materials and more energy efficient equipment, alternative ways to provide power, and remotely controlled equipment or even equipment that controls itself.

When it comes to energy supply and efficiency, the recent boom in renewable solar and wind technologies with much less environmental impact may be used for power supply at remote locations, thus eliminating traditionally complicated and costly logistics of fuel transportation to remote locations. Furthermore, equipment and facilities are becoming increasingly power efficient. The increase in polar orbiting satellites improves communication and increases the number of satellite images available so that weather and ice conditions can be better monitored in polar regions. The rapid technological development for space and underwater explorations has brought new technologies to remotely control field equipment and infrastructure. Combined with Artificial Intelligence (AI), some field equipment is nowadays not even depending on constant bandwidth connection anymore. Already today, drones are doing what previously required helicopters or aircraft. Thus, polar research will likely become more automated in the future. The very rapid development in the domain of remotely controlled equipment and infrastructure brings a lot of opportunities and possibilities but it also makes it important for project managers to have a technical background and to stay updated on new technologies including their limitations. Therefore, project management in the field will become even more important as will the need for interaction between project managers to exchange experiences and share information.

Survey results (Sect. 4) also indicate funding as the biggest challenge when it comes to infrastructure. To reduce these costs, a collaborative use of available facilities and coordination of transportation alternatives such as in Ny Ålesund (Sect. 2.3) is required. A major benefit for countries and operators of Antarctic stations is the Antarctic Treaty that strongly encourages international collaboration (see above Sects. 2 and 5.1). Well-established structures are already in place on an operational level to exchange ideas, visit other stations and collaborate on infrastructure. For example, the 
Council of Managers of National Antarctic Programs (COMNAP) is responsible for overall collaboration and coordination in Antarctica. The Dronning Maud Land Air Network (DROMLAN) is focused on regional collaboration in Dronning Maud Land and meets twice a year to discuss operational matters and challenges. Similarly well-established and strong collaborations, on an operational level, are still lacking in the Arctic, likely because operating in the Arctic is often cheaper due to easier access and already available infrastructure. As the Arctic is strategically more important, politics and national interests might not encourage interaction in the same way as the Antarctic Treaty does.

To further reduce costs of infrastructure and logistics, mechanisms such the ones developed in Ny Alesund (Sect. 2.3) could widely be adapted with coordination of transportation and access to field sites, as well as funding mechanisms to support access to infrastructure.

\subsection{Community Engagement}

A team consists of two or more individuals with different roles and responsibilities who interact socially and interdependently within an organization to perform tasks and accomplish common goals (National Research Council, 2015). Projects are temporary communities or organizations, or even miniature societies (Lundin and Söderholm, 1995; Perryman, 2013), with individuals working together in a team towards this common goal. Project-based communities need to be built and have to be sustained in order for the projects to be eventually proposed and initiated. Putting communitybuilding first allows for improved collaboration and project co-design. Almost any collaborative project in polar sciences is interorganizational in character (Sydow and Braun, 2018), with multiple institutes and organizations usually being involved. Crossing organizational boundaries in polar-science activities therefore need to be taken into account for engagement with a project-based community (Sydow and Braun, 2018).

Rigorous discussion around community engagement is a nascent field (Kuo, 2018), especially in polar science, as is evidenced by the fact that only $3 \%$ of survey respondents self-define themselves as community managers, and $16 \%$ as community managers and project managers (Fig. 3).

According to the AAAS Community Engagement Fellows Program (AAAS CEFP, 2018), community engagement involves the participation of members of a community in the community's activities where a community manager is someone who facilitates the activities of the community and the interactions between community members (AAAS CEFP, 2018). Community managers are responsible for fostering community among colleagues working on the same topic (Kuo, 2018), or helping people find shared topics to work on. This is an intentionally broad definition, and may include diverse activities such as supporting multi-institutional research collaboration (Sect. 2); connecting individuals as part of the member engagement and marketing activities of a professional scientific society or association; bringing together like-minded professionals as part of a science-focused community of interest or practice; bridging between an organization and others as part of a local, national, or international project involving scientists, policy makers, think tanks and others; or activities that may be described as "team science" (AAAS, 2018).

According to the "Hub for the Community Industry" (CMX), community managers require excellent organizational skills, creativity, curiosity, an analytical mind, passion and loyalty, patience, empathy, business savvy, and vision (Bridge, 2017). In an AAAS survey of scientific community managers, engagement and content skills were identified as most important, followed by strategic and technical skills, and business skills (Woodley et al., 2018). This changes over the course of a community manager's career; despite engagement being seen as a core competency, senior scientific community managers do more strategy and content work while newer community managers are more involved in direct engagement (Trellis, 2016a).

Scientific community manager's skills are often selftaught and with a science degree, or even a $\mathrm{PhD}$, because they identify with the scientific community that they support (Trellis, 2016b). This highlights the fact that community managers must develop the skills identified above, but this may be detrimental to short-term projects not long enough to allow for skill and knowledge building.

Project management is, for the most part, an activity undertaken with a community of others. By contrast, a community manager may or may not feel or be seen as part of this community. This is especially the case where managers operate in an environment where they "have far less authority than responsibility" (Project Management Institute, 2014). Community mangers often face large responsibilities but with an expectation of being invisible at the same time, endeavoring to shepherd or lead communities from behind. In these situations, it is important for a community manager to identify their connections within their professional community to be able to thrive in their role.

Many scientific communities do not have a community manager. Project managers may fill some community management tasks, but in such cases community-building is a by-product rather than the explicit goal. In this context, most scientific communities are not familiar with the role of community manager or do not prioritize this while some communities do not have a community manager due to lack of funding (Trellis, 2016c). When funding is available for a community manager, the source of the funding depends on the type of organization; academic institutions may be able to sustain long-term community managers, while research projects are more limited to shorter term funding (Trellis, 2016d).

This paper's survey also identified funding as the largest challenge for polar science community managers (Fig. 10). Stakeholder engagement, strategic planning, and external 
communication are also challenges for those who answered the survey. According to a broader survey of scientific community managers done by AAAS $(86 \%$ of whom were funded, therefore obviating funding as a challenge), prioritization of tasks was seen as the largest challenge (Trellis, 2016e). Interestingly, this could be seen as a project management task more than a community challenge; the fact that many identified their role as part-time could contribute to prioritization as a challenge. In the AAAS survey, development of engagement, strategic, and content skills, as well as technical and business skills, were also all seen as challenges as well (Trellis, 2016e).

Even more than the rest of the global science endeavour, polar sciences are highly interdisciplinary and international. With diverse and often diffuse teams, community management is crucial for sustained success in polar science, in particular for initiating and growing large international and interdisciplinary projects. Community efforts provided in part by, for example, the International Arctic Science Committee, were able to amplify the enthusiasm of a few researchers into the one hundred million Euro MOSAiC expedition by facilitating planning and implementation workshops. Community efforts were central to the success of the 2007-2008 International Polar Year (ICSU-WMO, 2011). Polar research is complicated but remains a human endeavour, and therefore dedicated facilitation of the relationships between collaborators leads to more successful science by encouraging more cross-disciplinary approaches and solutions.

Polar science balances an interesting dichotomy of being highly tele-connected while at home, but often very disconnected when conducting remote fieldwork. The AAAS survey identified that community managers promote more activities that call for online participation (Trellis, 2016f), which can both be better and less suited to polar communities, depending on the fieldwork calendar. The bimodal behaviour of researchers can be a unique challenge faced by polar community managers because organizing things while people are in the field makes tasks a lot more challenging.

In contrast, fieldwork (which may or may not be facilitated by a community manager or project manager) can build strong bonds which are crucial to cohesive polar science communities. In the field, "the commitment of participants to a project especially under extreme conditions, such as a polar expedition, has a vital bearing on its end result. In a project, an individual's performance depends more on actual commitment than on intrinsic skills and suitability for the functions the project requires" (Récopé et al., 2010). Whether in the field or not, a shared mental model of the work is also critical to overall success. Aligning a group's tasks, expectations, and goals is a key role where community management can help build both shared vision and shared value. In both, the field and in mental modelling, identifying the importance of community has been key to polar science; thus, community managers are also a key to successful polar science.
Community management is a field which is only beginning to be professionalized. In polar science, community managers have an important role to play. With challenges including dedicated roles or funding, as well as appropriate training, there is a lot of room for growth in polar science community management and therefore room for continued improvement of facilitation of polar science itself. It is therefore important to identify and recognize the presence and value of scientific community management tasks and roles being filled in polar sciences. Once they are enumerated and professionalized, it is possible to both fund and evaluate the effectiveness of scientific community managers. Skills development is crucial for successful community managers. Whether polar scientists transitioning into a community management role or community managers learning about polar science and polar science project management, it will be increasingly important to establish training and networking opportunities for this community which serves the polar science community.

\section{Final Remarks}

There is only a limited amount of literature available so that this paper presents a first comprehensive overview of the challenges related to managing polar research projects. Survey results do not necessarily represent the opinion of the full global community of community and project managers active in polar research. This survey, however, has been a first-ever attempt to gauge information from the community of project and community managers in polar science; and the number of 284 participants demonstrates the positive response and interest in the topic. Future analysis of various free-text responses to open-ended questions (for an example see Table 1) will help to obtain a deeper understanding of the various challenges faced by project and community managers in polar sciences as not all of them could be considered in this paper.

Successful polar research requires skilful scientific project management as planning and implementation of polar science projects often involve many uncertainties. Here, we have addressed the main challenges of polar science project management identified through survey responses, in addition to the authors' various professional project and community management experiences. Four overarching, most challenging themes in polar science project management have been identified: international cooperation, interdisciplinarity, infrastructure, and community management.

Funding was identified by survey respondents as a common challenge for all themes. Accessibility to funding is considered challenging for international cooperation as research funds are still mostly provided by national institutions or governments. While efforts to support interdisciplinary projects are growing, financial support for projects involving various science disciplines is still seen as challenging 
as reviewers of an interdisciplinary science project may still be biased by their own traditional discipline-specific background. Funding availability, or the lack thereof, is also considered by project managers as the major challenges when it comes infrastructure access and logistics in both Arctic and Antarctica, mainly due to their high costs. A better coordinated use of existing infrastructure and logistics is one of the key solutions. Furthermore, the lack of funding is an issue for community managers as many scientific communities are not familiar with the role of a community manager and do not prioritize this for their scientific communities.

To overcome the challenges faced by polar project and community managers, it is important to identify and recognize the value of scientific project and community management tasks and roles being filled. Often, project and community management in academia is undervalued and viewed by scientists as merely administrative tasks that can be carried out by principal scientists in addition to their role in research. A cultural change is therefore necessary to fully acknowledge the roles and work of project and community managers and their contribution to polar research, and potentially to create financial mechanisms on both national and international levels to support professional managers in light of their increasing role in polar sciences.

Skills development is crucial for both project and community managers. Both roles cannot simply rely on an individual's organisational and interpersonal skills, but require structured training. This includes technical training for e.g., finance, programming, instrumentation, software, project management systems, etc. but also strategic and interpersonal skills such as conflict management, team management, leadership and policy.

As many project managers do not feel that their authority being sufficiently recognised within the project, it would be advantageous for them to become more involved in the decision-making process for all strategic decisions related to the project; for example, by including them in the project executive boards or advisory committees also acknowledging the scientific expertise that project managers in academia often have.

To successfully guide a polar research endeavour, both project managers and community managers should be involved in polar research activities from the very beginning. Often, they are hired only for the implementation phase after the project has already been initiated and funded. It is therefore important for polar research institutions to establish long-term project management offices where project managers can support research activities from the conception of the project until its closure with a prominent role in all phases.

Finally, as a general recommendation, given the sparseness of literature on polar science project and community management, more in depth analysis is needed for the topics addressed in this paper to grow the current body of literature and provide guidelines that project and community management in polar research can refer to.

Data availability. Partial data from the survey is provided here in the Supplement for the manuscript. Open-ended questions, comments and contact information of respondents have been removed to ensure compliance with the privacy and impact statements declared in the introduction of the survey.

Supplement. The supplement related to this article is available online at: https://doi.org/10.5194/adgeo-46-25-2019-supplement.

Author contributions. All co-authors significantly contributed to the design of the survey and to discussions resulting in the paper. KW and LS initiated discussion around the topic and invited coauthors to join this effort. YZ led the design of the survey and analyzed results of the survey. LS carried out a major literature review. YZ, AP, SL, AP, RB, and MB wrote certain sections of the paper. As lead author, KW coordinated the contributions, wrote and edited main parts of the paper and produced Figs. 3 to 10 (survey results). AP and SL provided Figs. 1 and 2, respectively.

Competing interests. The authors declare that they have no conflict of interest.

Special issue statement. This article is part of the special issue "Project management in geosciences: systems and practices for high-impact research". It is a result of the session "Project Management in the Arctic Science - the Unknown Driver of Changes" during the Arctic Science Summit Week 2017, Prague, Czech Republic, 31 March-7 April 2017.

Acknowledgements. We are grateful for thorough comments and suggestions by three anonymous reviewers. David Carlson provided guidance and recommendations for the idea of the paper. We thank Harald Steen and Stephen Hudson (both Norwegian Polar Institute) for helpful comments regarding the management of infrastructure on Svalbard. Alexey K. Pavlov was supported by the Polish-Norwegian Research Programme operated by the National Centre for Research and Development under the Norwegian Financial Mechanism 2009-2014 in the frame of Project Contract Pol-Nor/197511/40/2013, CDOM-HEAT. Luisa Cristini received funding through the EU Horizon 2020 (APPLICATE 727862).

The article processing charges for this open-access publication were covered by a Research Centre of the Helmholtz Association.

Review statement. This paper was edited by Sylvia Walter and reviewed by Fiona Tummon and two anonymous referees. 


\section{References}

AAAS: AAAS State of Scientific Community Management Survey, available at: https://www.surveygizmo.com/s3/2642025/ AAAS-State-of-Scientific-Community-Management-Survey, last access: 28 June 2018.

AAAS CEFP: Community Engagement Fellows Program, American Association for the Advancement of Science, available at: https://www.aaas.org/cefp/what-is-community-engagement, last access: 13 June 2018.

Antarctic Treaty: Original version from 1 December 1959, available at: https://www.ats.aq/documents/ats/treaty_original.pdf (last access: 29 June 2018), 1959.

Antarctic Treaty Secretariat: https://www.ats.aq/index_e.htm, last access: 23 April 2019

Arctic Council: Agreement on Enhancing International Arctic Scientific Cooperation, available at: https://www.state.gov/e/oes/rls/ other/2017/270809.htm (last access: 23 April 2019), 2017.

Aubry, M. and Lièvre, P.: Ambidexterity as a competence of project leaders: a case study from two polar expeditions, Proj. Manag. J., 41, 32-44, 2018.

Barr, S. and Lüdecke, C. (Eds.): The History of the International Polar Years (IPYs), Springer Science \& Business Media, Berlin, Heidelberg, 2010.

Bridge, R.: The 9 Skills Every Community Manager Needs, available at: https://cmxhub.com/article/the-9-skills-everycommunity-manager-needs/ (last access: 28 June 2018), 2017.

Cannegieter, H. G.: The History of the International Meteorological Organization 1872-1951, Annalen der Meteorologie, 1, 1-280, 1963.

Check, J. and Schutt, R. K.: Survey research, in: Research methods in education, edited by: Check, J. and Schutt, R. K., Sage Publications, Thousand Oaks, CA, 159-185, 2012.

Dewulf, A., François, G., Pahl-Wostl, C., and Taillieu, T.: A framing approach to cross-disciplinary research collaboration: experiences from a large-scale research project on adaptive water management, Ecol. Soc., 12(2), 14, available at: http://www.ecologyandsociety.org/vol12/iss2/art14/ (last access: 23 April 2019), 2007.

Ernø-Kjølhede, E.: Project Management Theory and the Management of Research Projects, Working Papers 3/2000, Copenhagen Business School, Department of Management, Politics \& Philosophy, available at: https://ideas.repec.org/p/hhb/cbslpf/2000_ 003.html (last access: 23 April 2019), 2000.

Gerson, N. C.: From polar years to IGY, Adv. Geophys., 5, 1-52, 1958.

ICSU and WMO: Understanding Earth's Polar Challenges: International Polar Year 2007-2008, available at: https://council.science/publications/understanding-earths-polarchallenges-international-polar-year-2007-2008 (last access: 23 April 2019), 2011.

INTERACT: INTERACT Management planning for arctic and northern alpine research stations - Examples of good practices, edited by: Topp-Jørgensen, E., Rasch, M., Elger, K., Warwick, V., and Barnard, C., DCE - Danish Centre for Environment and Energy, Aarhus University, Denmark, 324 pp., 2014.

Jeffrey, P.: Smoothing the Waters: Observations on the Process of Cross-Disciplinary Research Collaboration, Soc. Stud. Sci., 33, 539-562, 2003.
Kloppenborg, T. and Opfer, W.: The current state of project management research: Trends, interpretation and predictions, Proj. Manag. J., 33, 5-18, 2002.

Kridelbaugh, D.: How Project Management Techniques Can Improve Research, Lab Manager, available at: https://www.labmanager.com/business-management/2017/01/ how-project-management-techniques-can-improve-research/ 50\T1\textbackslash\%20T1/textbackslash\#.XL8RSKZS8-V, last access: 23 April 2019.

Kuo, M.: Building community as a career, Science Careers, available at: http://www.sciencemag.org/careers/2018/02/ building-community-career, last access: 13 February 2018.

Liu, J., Dietz, T., Carpenter, S. R., Alberti, M., Folke, C., Moran, E., Pell, A. N., Deadman, P., Kratz, T., Lubchenco, J., Ostrom, E., Ouyang, Z., Provencher, W., Redman, C. L., Schneider, S. H., and Taylor, W. W.: Complexity of Coupled Human and Natural Systems, Science, 317, 1513-1516, 2007.

Lundin, R. A. and Söderholm, A.: A theory of the temporary organization, Scandinavian Journal Management, 11, 437-455, 1995.

Mervis, J.: IPY means doing what it takes to get to the ends of the Earth, Science, 315, 1514-1517, https://doi.org/10.1126/science.315.5818.1514, 2007.

Nath, I. and Winnacker, E.-L.: Promoting responsible conduct while doing global science, Curr. Sci., 111, 787-788, 2016.

National Research Council: Enhancing the Effectiveness of Team Science, The National Academies Press, Washington, DC, https://doi.org/10.17226/19007, 2015.

Peeken, I.: The Expedition PS92 of the Research Vessel POLARSTERN to the Arctic Ocean in 2015, Berichte zur Polar- und Meeresforschung, Alfred Wegener Institute for Polar and Marine Research, Bremerhaven, Germany, 694, 153 pp., 2016.

Perryman, M.: Scientific Project Management, Department of Astrophysical Sciences, Princeton University, available at: https://www.astro.princeton.edu/ strauss/perryman/ perryman-scientific-projman (last access: 29 June 2018), 2013.

Project Management Institute: Ethics Member Advisory Group Project Management Institute: Quiet Leadership Tips for Project Success: How Leading Quietly Saved the Men of the Shipwrecked Endurance, Paper presented at PMI ${ }^{\circledR}$ Global Congress 2014 - North America, Phoenix, Arizona, Newtown Square, PA: Project Management Institute, available at: https://www.pmi.org/ learning/library/leading-quietly-saved-shipwrecked-men-9309 (last access: 28 June 2018), 2014.

PPP-SG: YOPP Implementation Plan v2.0 (WWRP Polar Prediction Project Implementation Plan for the Year of Polar Prediction (YOPP) Version 2.0, World Meteorological Organization, Geneva, Switzerland, available at: http://www.wmo.int/pages/prog/arep/wwrp/new/documents/ FINAL_WWRP_PPP_YOPP_Plan_28_July_web.pdf (last access: 23 April 2019), 2016.

Project Management Institute: A Guide to the Project Management Body of Knowledge (PMBOK ${ }^{\circledR}$ Guide) - Sixth Edition, Project Management Institute, Newtown Square, PA, 756 pp., 2017.

Récopé, M., Lièvre, P., and Rix-Lièvre, G.: The commitment of polar expedition members to a project: declared motivation or in situ mobilization?, Proj. Manag. J., 41, 45-56, https://doi.org/10.1002/pmj.20182, 2010.

Shore, B. and Cross, B. J.: Exploring the role of national culture in the management of large-scale interna- 
tional science projects, Int. J. Proj. Manag., 23, 55-64, https://doi.org/10.1016/j.ijproman.2004.05.009, 2005.

Svalbard Treaty: Treaty of 9 February, 1920, relating to Spitsbergen, available at: https://app.uio.no/ub/ujur/oversatte-lover/data/ lov-19250717-011-eng.pdf (last access: 7 March 2019), 1920.

Sydow, J. and Braun, T.: Projects as temporary organizations: An agenda for further theorizing the interorganizational dimension, Int. J. Proj. Manag., 36, 4-11, 2018.

Trellis: Exploring scientific community managers' skill sets, available at: https://blog.trelliscience.com/exploring-scientificcommunity-managers-skill-sets/ (last access: 28 June 2018), 2016a.

Trellis: Scientific community managers: often self-taught with a science $\mathrm{PhD}$, available at: https://blog.trelliscience.com/scientificcommunity-managers-often-self-taught-with-a-science-phd/ (last access: 28 June 2018), 2016b.

Trellis: Many organizations have communities. Why don't they all have community managers?, 1 August 2016, available at: https://blog.trelliscience.com/many-organizations-havecommunities-why-dont-they-all-have-community-managers/ (last access: 28 June 2018), 2016c.

Trellis: A closer look at the funding landscape for scientific community managers, available at: https://blog.trelliscience.com/acloser-look-at-the-funding-landscape-for-scientific-communitymanagers/ (last access: 28 June 2018), 2016d.
Trellis: Scientific community managers' top challenges and training needs, available at: https://blog.trelliscience.com/scientificcommunity-managers-top-challenges-and-training-needs/ (last access: 28 June 2018), 2016 e.

Trellis: How scientific community managers shape activity planning, available at: https://blog.trelliscience.com/how-scientificcommunity-managers-shape-activity-planning/ (last access: 28 June 2018), 2016f.

Werner, K., Fritz, M., Morata, N., Keil, K., Pavlov, A., Peeken, I., Nikolopoulos, A., Findlay, H.S., Kedra, M., Majaneva, S., Renner, A., Hendricks, S., Jacquot, M., Nicolaus, M., O’Regan, M., Sampei, M., and Wegner, C.: Arctic in Rapid Transition: Priorities for the future of marine and coastal research in the Arctic, Polar Sci., 10, 364-373, 2016.

Werner, K., Goessling, H., Hoke, W., Kirchhoff, K., and Jung, T.: Polar Prediction Project Management - From Research to Polar Environmental Safety, Arctic Science Summit Week 2017, Oral Presentation, Prague, Czech Republic, 2017.

Woodley, L., Binder, M., O’Donnell, S., Olds, H., Pope, A., Rabinowitz, G., and Volchok, R.: American Association for the Advancement of Science (AAAS) Community Engagement Fellows Program (CEFP) Advocacy/Ambassador Program Survey, v2, DataONE Dash, Dataset, https://doi.org/10.15146/R3TH6F, 2018. 